\title{
Arqueología y restauración en Calatrava la Vieja (Carrión de Calatrava, Ciudad Real)
}

\section{Miguel Ángel Hervás Herrera ${ }^{a}$}

${ }^{a}$ Baraka Arqueólogos, S.L., Carretera de la Atalaya 30, 13005 Ciudad Real. mangelhervas@yahoo.es

\begin{abstract}
Resumen
Las intervenciones desarrolladas en las últimas décadas en Calatrava la Vieja (Carrión de Calatrava, Ciudad Real) han permitido obtener un importante volumen de conocimiento histórico, rescatar un amplio conjunto de materiales arqueológicos, y consolidar, proteger y poner en valor las ruinas, lo que a su vez hizo posible la incorporación del yacimiento al Parque Arqueológico de Alarcos-Calatrava desde el momento de creación de este último en 2003, y lo ha convertido en uno de los yacimientos visitables más destacados de la región.

En las páginas que siguen haremos un repaso de las principales actuaciones llevadas a cabo en materia de investigación y conservción en el marco del plan general de intervenciones sistemáticas del yacimiento, expondremos los criterios aplicados, y valoraremos el papel de la arqueología en el proceso de restauración llevado a cabo.
\end{abstract}

Palabras clave: Calatrava la Vieja, parque arqueológico, fortificación, investigación, conservación, restauración.

\begin{abstract}
The interventions carried out over the last few decades in Calatrava la Vieja (Carrión de Calatrava, Ciudad Real) have made it possible to obtain a significant amount of historical knowledge, rescue a wide range of archaeological materials, and consolidate, protect and enhance the value of the ruins. This in turn made it possible to incorporate the site into the Alarcos-Calatrava Archaeological Park from the time the latter was created in 2003, and has made it one of the most outstanding open to the public sites in the region.

In the following pages we will review the main actions carried out in terms of research and conservation within the framework of the general plan of systematic interventions at the site, we will explain the criteria applied, and we will assess the role of archaeology in the restoration process carried out.
\end{abstract}

Keywords: Calatrava la Vieja, archaeological park, fortification, research, conservation, restoration. 


\section{Introducción}

El enclave de Calatrava la Vieja desempeñó un papel protagonista en el poblamiento de la región del Alto Guadiana durante siglos, lo que se debió a su situación estratégica junto a uno de los principales vados de este tramo del río, y a su consiguiente vinculación a la red viaria que articuló la explotación económica, la estructura administrativa y la defensa militar del territorio a lo largo de su historia (Fig. 1). Habitado al menos desde la Edad del Bronce, albergó sucesivamente un oppidum o ciudad amurallada en época ibérica, un pequeño asentamiento romano de vocación agropecuaria con continuidad durante el periodo visigodo, la capital islámica de la zona durante casi cinco siglos, una fortaleza templaria, y el convento fundacional de la orden militar de Calatrava, la primera autóctona de la Península Ibérica. Calatrava la Vieja fue abandonada casi por completo a comienzos del siglo XV, y alcanzó el último cuarto del siglo XX semioculta por sus propios derrumbes, si bien permanecían visibles algunas estructuras de grandes proporciones - principalmente defensivas - que se encontraban aquejadas por graves problemas de conservación (Hervás, 2016, pp. 63-156) (Fig. 2).

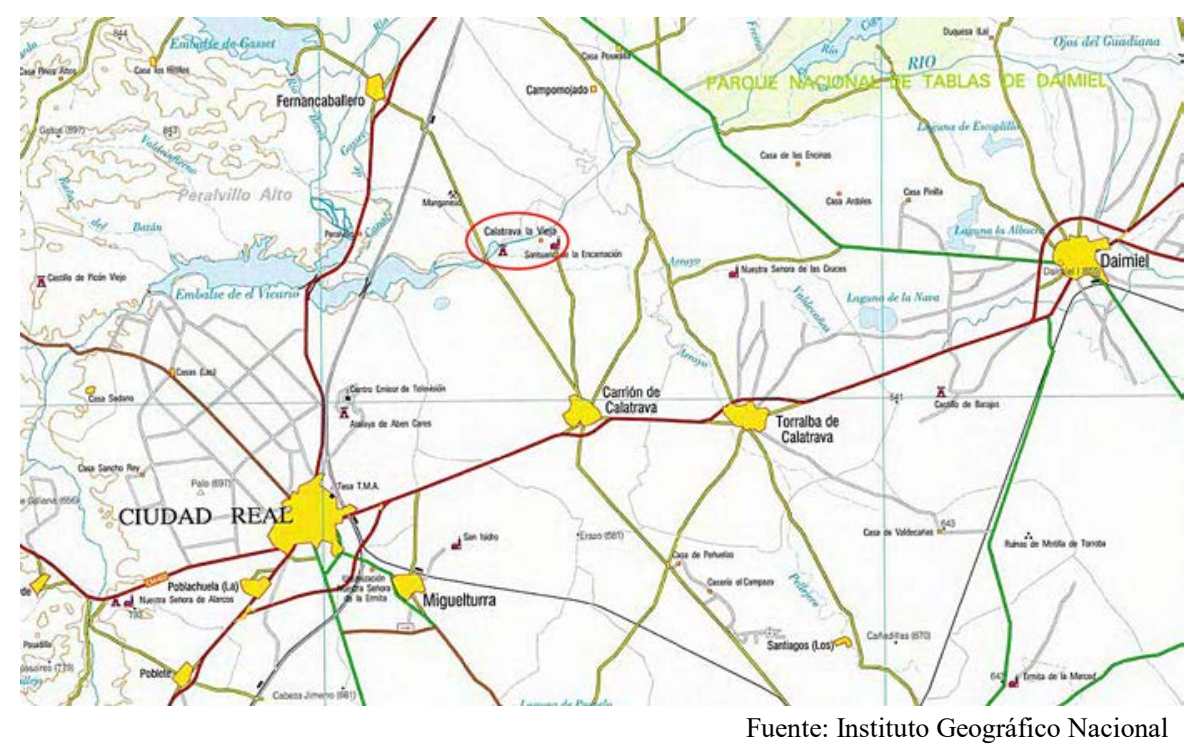

Fig. 1 Mapa de localización de Calatrava la Vieja

\section{Antecedentes}

Aunque los primeros trabajos de restauración en Calatrava la Vieja no se acometieron hasta 1975, la conciencia de la importancia del lugar y de la necesidad de intervenir en él encuentra su punto de partida en la promulgación del Decreto de 22 de abril de 1949 sobre protección de los castillos españoles, y se despierta a comienzos de la década de 1950. Pero las primeras propuestas concretas de inversión en la antigua ciudad islámica no llegaron hasta el año 1964, y lo hicieron de la mano de los programas de restauración de castillos elaborados por la Comisaría General del Servicio de Defensa del Patrimonio Artístico Nacional, que previeron la inversión de entre dos y cuatro millones de pesetas para trabajos de restauración en el lugar entre los años 1964 y 1968 (Hervás, 2016, pp. 220-222). En cualquier caso, estas propuestas no llegaron a materializarse, y el yacimiento continuó en estado de abandono durante una década más.

Entre 1975 y 1996 se ejecutaron cuatro intervenciones de restauración orientadas a la solución de problemas de conservación apremiantes en estructuras de gran volumen, y ajenas al plan general de intervenciones sistemáticas iniciado en 1984. Se trata de obras proyectadas a corto plazo, sin perspectivas de continuidad en el tiempo, desligadas entre sí, y que no responden a un plan director o a un programa de intervención unitario. Ninguna de ellas estuvo precedida por estudios histórico-arqueológicos específicos, ni acompañada por trabajos de documentación de la propia restauración. Tampoco los criterios de intervención aplicados — cambiantes entre las diferentes actuacionesrespetaron la realidad constructiva original de las fábricas tratadas ni las secuencias estratigráficas murarias, y los movimientos de tierra necesarios en cada caso se realizaron sin el debido control arqueológico (Hervás, 2016, pp. 213$341)$. 


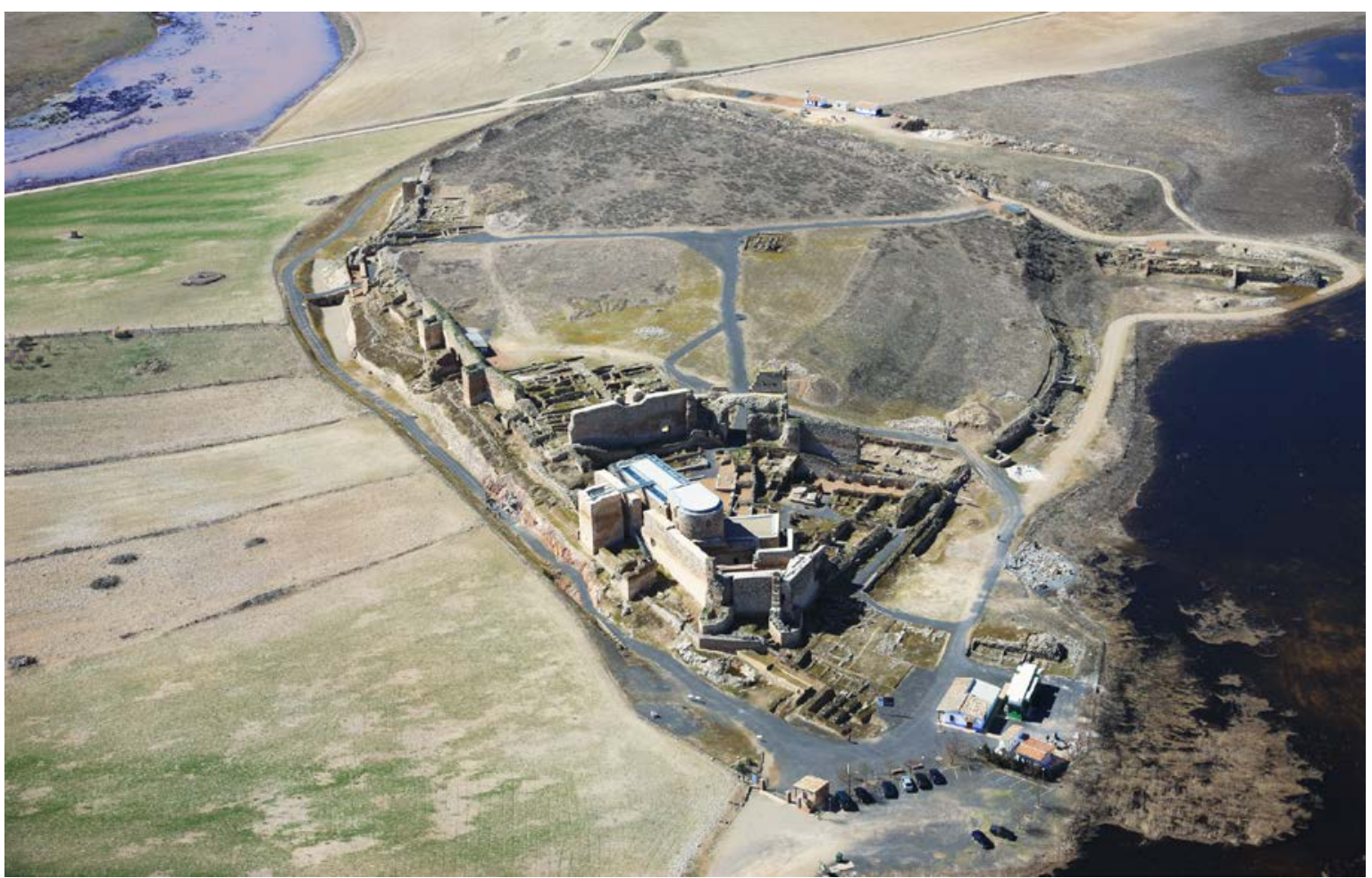

Fuente: MAC Fotográfica (2009)

Fig. 2 Vista aérea del recinto amurallado

\section{Intervenciones sistemáticas. El Plan general}

Las intervenciones arqueológicas realizadas en el lugar desde 1984 permitieron no sólo obtener un profundo conocimiento sobre su historia y su realidad constructiva y estratigráfica, sino también poner las bases para el desarrollo de las intervenciones de conservación y restauración que se desarrollaron desde 1997 y culminaron con la museización del lugar y su incorporación al Parque Arqueológico de Alarcos-Calatrava a partir de 2003 (Fig. 3). La investigación arqueológica desempeñó en este proceso un papel primordial, pues se situó en el punto de partida del plan general de intervención, y resultó decisiva tanto para la definición de los criterios de restauración a aplicar, como para la elaboración de los recorridos de visita y sus contenidos.

Estas actuaciones forman parte de lo que hemos dado en llamar el plan general de intervenciones sistemáticas (Hervás, 2016, pp. 343-445), articulado en función de tres programas interdependientes que se corresponden con cada uno de los principios animadores del plan: investigación, restauración, y difusión. Cada programa se desarrolla, a su vez, a partir de proyectos de actuación concretos, coordinados entre sí, y dirigidos por equipos técnicos y científicos compartidos, con continuidad a lo largo del tiempo. Todas estas intervenciones fueron financiadas con fondos públicos, tanto de la Unión Europea como del Gobierno de Castilla-La Mancha.

Investigación, restauración y difusión configuran un circuito de retroalimentación: investigar para restaurar, e investigar y restaurar para difundir. En efecto, los trabajos de investigación permiten no sólo obtener un determinado volumen de conocimiento histórico que después podrá ser difundido, sino también ajustar las restauraciones de un modo muy preciso a la realidad física - material y estratigráfica — de las estructuras sobre las que se interviene. Los trabajos de restauración, a su vez, permiten plantear y resolver determinadas cuestiones relativas a la historia de la construcción, y generan nuevos conocimientos de carácter científico sobre la cultura material del pasado. Investigación y restauración unidas, por último, permiten llenar de contenidos los recorridos de visita — carteles explicativos, recuperación de volúmenes perdidos...-, y difundir el conocimiento adquirido en congresos, ciclos de conferencias, y publicaciones diversas, tanto especializadas como de divulgación (Hervás et al., 2006, p. 87). 
En función de todo ello, podemos enunciar del siguiente modo los tres objetivos generales básicos que animan desde un principio el plan de intervenciones sistemáticas:

- obtener un determinado volumen de conocimiento histórico de calidad científíca;

- recuperar los valores monumentales del yacimiento;

- museizar y poner en valor los restos recuperados.

Desde 1997 las intervenciones se realizaron según un plan de actuación común con Alarcos, adecuadamente consensuado entre las direcciones científicas de ambos yacimientos. La vinculación entre Alarcos y Calatrava no es un mero accidente del plan general de intervención, sino que tiene raíces profundas: se trata de dos grandes yacimientos medievales situados en el centro de la provincia de Ciudad Real, junto a la margen izquierda del río Guadiana, cuya historia es fiel exponente de los cambios operados en al-Andalus entre los siglos VIII y XIII. Ambos quedaron unidos a partir de 2003 por la figura del Parque Arqueológico, pero previamente habían estado vinculados entre sí por muchos siglos de historia en común — desde la protohistoria hasta el siglo XIII—, por el arco que describe el Guadiana en esta zona en su doble papel de vía de comunicación y de frontera - lo que daba sentido y valor estratégico a ambos emplazamientos - , y por más de veinte años de investigación en paralelo, los últimos catorce de los cuales (1997-2010) se desarrollaron en el marco de un único programa común que desembocó en la creación del Parque Arqueológico (Hervás et al., 2006, p. 86).

\subsection{Investigación}

El programa de investigación (1984-2010 y 2014-2019) se ha desarrollado en 34 campañas de diversa duración, a razón de una por año, salvo en 1995, en que se acometieron tres. Avaladas primero por el Museo Arqueológico Nacional de Madrid y después por el Museo Provincial de Ciudad Real, fueron dirigidas siempre por un mismo equipo de investigadores, y estuvieron financiadas por el Gobierno de Castilla-La Mancha.

Las excavaciones arqueológicas realizadas dentro de este programa permitieron alcanzar un profundo conocimiento de la realidad histórica y material del yacimiento y pusieron al descubierto numerosas estructuras de gran valor patrimonial, necesitadas de trabajos de conservación y consolidación. Por otra parte, los conocimientos adquiridos constituyeron la base sobre la que se establecieron tanto los criterios de restauración generales como las pautas a aplicar en cada caso concreto, que quedaron bajo la responsabilidad de los arqueólogos directores de la investigación (Hervás et al., 2006, p. 93). Además, los numerosos datos obtenidos a lo largo de todo este proceso generaron un ingente corpus documental que sirvió de base, a su vez, para elaborar los contenidos del programa de difusión.

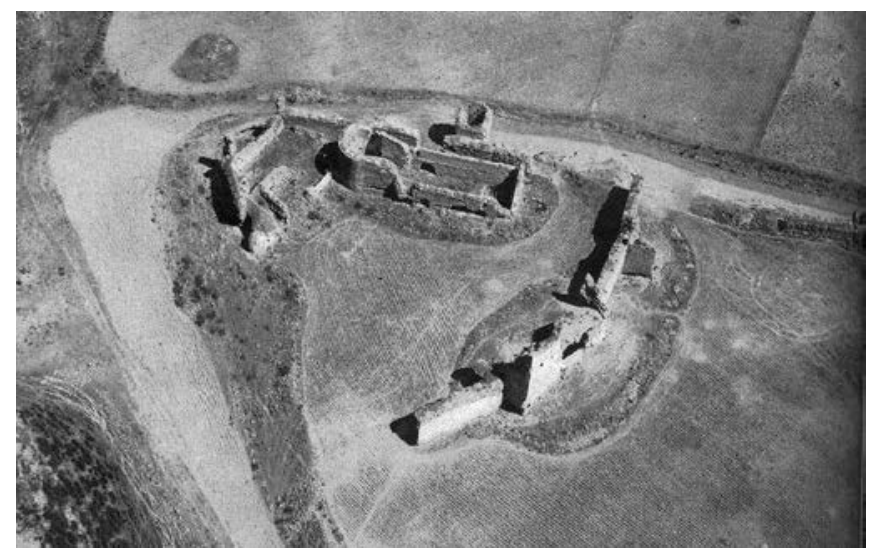

Fuente: Sarthou (1979)

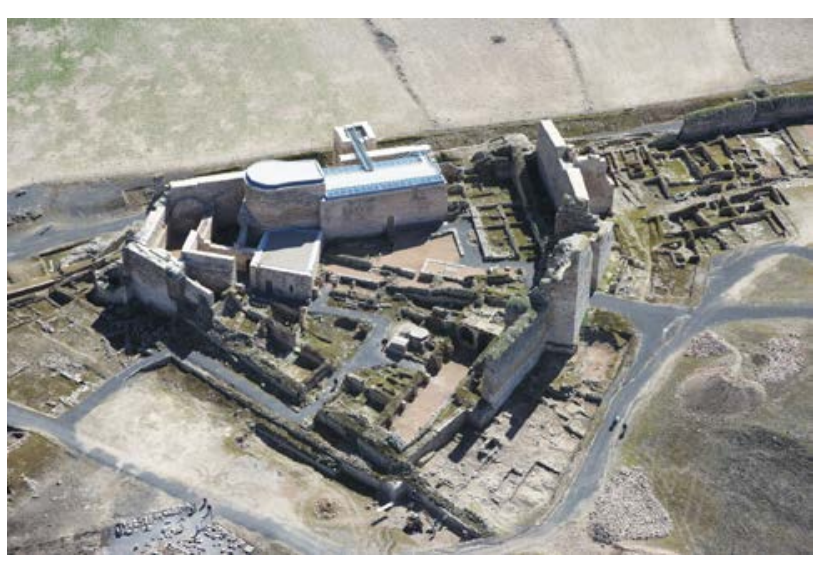

Fuente: MAC Fotográfica (2019)

Fig. 3 Vistas aéreas del alcázar de Calatrava la Vieja, antes de las intervenciones (izquierda), y después (derecha)

Entre 1984 y 1987, las intervenciones se llevaron a cabo mediante planes de empleo, en aplicación del convenio firmado entre la Comunidad Autónoma y el INEM. Entre 1988 y 1994 quedaron interrumpidas las aportaciones del INEM a Calatrava la Vieja, y las campañas de excavación se financiaron con cargo a los programas de ayuda a la investigación promovidos por el gobierno regional. Por último, los planes de empleo retornaron al yacimiento en 1995 , 
y permitieron la realización de nuevas intervenciones hasta 2010, en que quedaron interrumpidos de nuevo. Los trabajos de excavación se retomaron en 2014 mediante la fórmula de curso de arqueología para estudiantes universitarios, vigente en la actualidad. Hasta el momento, se ha excavado una superficie total de $22000 \mathrm{~m}^{2}$, lo que incluye alrededor de un $60 \%$ del perímetro amurallado, la totalidad del interior del alcázar, y un 10\% del interior de la medina.

En Calatrava la Vieja se excavó mediante la combinación de la estrategia en área abierta con el procedimiento estratigráfico. El objetivo de que el yacimiento no sólo pueda ser visitado, sino también entendido, obliga en primer término a excavar en grandes áreas abiertas, haciéndolo de modo que se pongan al descubierto, en fases sucesivas de la excavación, momentos de ocupación cronológicamente homogéneos. Esto facilita las labores de interpretación y la posterior musealización del conjunto. A modo de ejemplo, esta forma de proceder permitió recuperar, prácticamente completo, el nivel de ocupación de la Encomienda de Calatrava (siglos XIII-XV) en el interior del alcázar, e identificar tanto el edificio conventual como la explanada baldía situada al norte, que se formó a partir de los derrumbes de grandes edificios preexistentes y fue aprovechada por los monjes calatravos para la instalación de alfares (Fig. 4). Finalmente, y gracias a la infrautilización de dicha explanada en época de la Encomienda, fue posible excavar niveles inferiores sin necesidad de desmontar estructuras, de modo que se ha podido documentar buena parte de la distribución interna del alcázar en época islámica al mismo tiempo que se mantenía la coherencia del momento de ocupación cristiano.

Por su parte, el procedimiento estratigráfico permite: en primer lugar, recuperar la historia de la topografía del yacimiento, ya que se respetan al máximo las superficies de cada unidad estratigráfica; en segundo lugar, clasificar los objetos en función del estrato en el que quedaron sepultados, sin desplazarlos de su contexto natural; y por último, identificar las relaciones físicas entre unidades estratigráficas y, por consiguiente, conocer la cronología relativa de cada una de ellas en el mismo instante de ser excavada. La combinación de la estrategia en área abierta con el procedimiento estratigráfico permitió situar las estructuras en su contexto espacial más preciso, dado que se respetó escrupulosamente la topografía original de los niveles de uso asociados. Además, se recuperaron los recorridos históricos del monumento, que constituyen un elemento esencial para garantizar una correcta interpretación y musealización del conjunto.
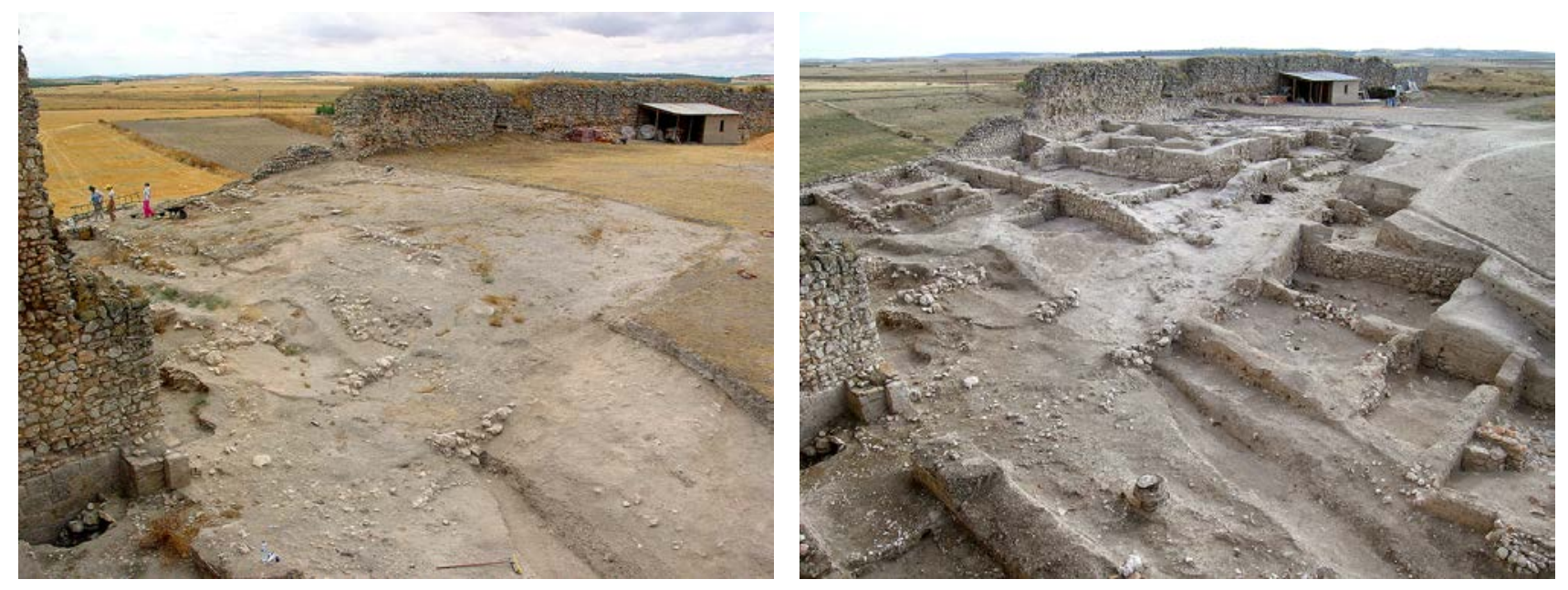

Fig. 4 El sector sureste de la medina, antes y después de su excavación mediante estrategia en área y estratigrafía natural

\subsection{Restauración}

Las restauraciones correspondientes al plan general comenzaron en 1997 con la incorporación de Calatrava la Vieja al ámbito de actuación de la Escuela-Taller de Alarcos, que trabajaba en el yacimiento homónimo desde 1990, y que contaba por tanto con una experiencia previa muy apreciable en cuanto a definición y aplicación de criterios. Entre 1997 y 2010 intervinieron en Calatrava la Vieja las Escuelas-Taller Alarcos III (1997-1998), Alarcos IV (2000-2002), Alarcos V (2003-2005), Alarcos VI (2005-2007), el Taller de Empleo del Parque Arqueológico (2007-2008), y la Escuela-Taller del Parque Arqueológico (2008-2010). Gracias a ello se fijaron los criterios y procedimientos de actuación, y se consolidaron y restauraron las torres pentagonales y la torre albarrana almohade del frente oriental del alcázar (Fig. 5), la torre pentagonal y la puerta en recodo de la medina, la sala de audiencias del interior del alcázar, las 
salas abovedadas del convento de los calatravos, y diversos lienzos y torres en todo el perímetro amurallado. Además, se construyeron las infraestructuras hoy existentes en el yacimiento, y se habilitaron los recorridos de visita.

La Escuela-Taller de Alarcos vinculó desde sus inicios los planes de formación y empleo en obra real con el patrimonio histórico, y lo hizo en dos de los yacimientos arqueológicos más importantes de la región (Alarcos y Calatrava la Vieja), en los que los trabajos de excavación estaban muy avanzados gracias a la aplicación previa del programa de investigación. Se perseguía la potenciación de ambos yacimientos arqueológicos como núcleos de relevancia histórica, el establecimiento de las condiciones necesarias para su visita y comprensión, y el desarrollo de programas de atracción y actividad turística en relación con el patrimonio cultural y natural de la comarca (Hervás et al., 2006, p. 94). Paralelamente, se revalorizaron los oficios artesanos y se desarrollaron programas de investigación en relación con técnicas antiguas de construcción (Rascón y Sánchez, 2000). Los trabajos de restauración ejecutados constituyeron, en sí mismos, prácticas de arqueología experimental. La continuidad del equipo técnico a lo largo del tiempo favoreció la coordinación de las distintas áreas de trabajo, y proporcionó a cada uno de sus componentes un nivel de conocimiento adecuado acerca del bien sobre el que se intervenía y de los objetivos perseguidos (Juan y Gómez, 2005; Juan, 2013).

Sin embargo, el programa de Escuelas Taller presentaba limitaciones derivadas de la dotación presupuestaria de cada proyecto, del tipo de mano de obra empleada y de la existencia de una determinada carga docente, aspectos que condicionaban el rendimiento e imponían restricciones en materia de seguridad. Estas circunstancias impedían actuar en obras de gran envergadura o excesiva complejidad técnica, y en las que presentasen riesgos significativos. Cuando en Calatrava la Vieja se abordaron proyectos de esas características, fue necesario recurrir a la ejecución por contrata, mediante el concurso de empresas especializadas en restauración arquitectónica.
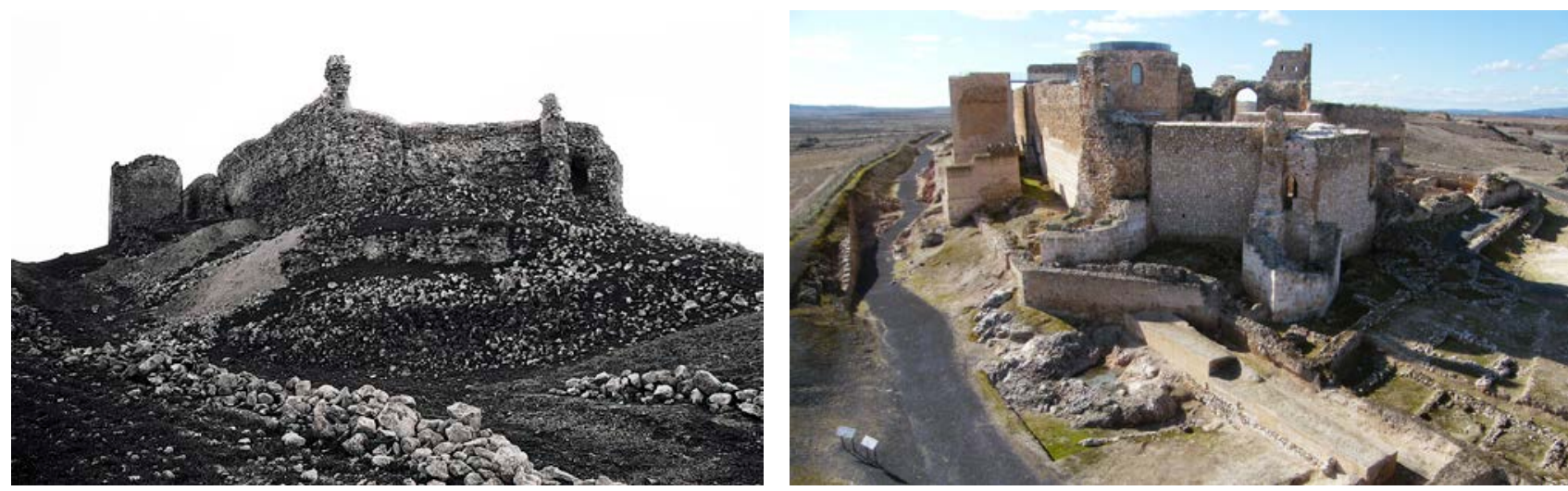

Fig. 5 El frente oriental del alcázar, antes y después de las intervenciones

En cualquier caso, sólo variaban la fórmula de gestión del proyecto, su tramitación administrativa y la entidad ejecutora. Los criterios y procedimientos de intervención y los mecanismos de control — fase de estudios previos, supervisión arqueológica y documentación del proceso - se aplicaban por igual tanto para estos proyectos como para los de Escuela Taller, y quedaban en ambos casos bajo la responsabilidad directa del equipo técnico y científico del yacimiento. Por medio del sistema de contrata se acometieron, en concreto: la restauración de la puerta islámica de comunicación entre el alcázar y la medina (2001); la consolidación y adecuación para visitas de la iglesia de los calatravos (2002); la adecuación arquitectónica de la iglesia de los calatravos (2006-2007); y la consolidación de las estructuras del sector cristiano del alcázar (2007-2008). Todas estas intervenciones fueron promovidas y financiadas por el gobierno regional en el marco del plan general de intervención del Parque Arqueológico Alarcos-Calatrava, con excepción de la última, que fue financiada con cargo a los fondos del 1\% cultural del Ministerio de Fomento.

\subsection{Objetivos, criterios y procedimientos de restauración del Plan General}

Se intervino sobre estructuras que habían perdido sus caras vistas por erosión, desplome o expolio de materiales. Se reponían las partes desaparecidas con la mayor fidelidad posible al original, sin recrecer la estructura por encima de la altura máxima conservada, y se diferenciaba la obra de restauración con respecto a la histórica mediante la interposición de estratos de intervención y marcas de contorno. Se trataba de proteger la obra original por medio de la superposición 
de la obra nueva, y recuperar volúmenes y lecturas perdidos para facilitar la percepción de su entidad arquitectónica, reduciendo al mínimo posible el impacto visual de la intervención. A partir de estos principios, se establecieron tres objetivos a alcanzar en cada una de las estructuras sobre las que se intervenía:

- Prevenir el deterioro del bien, mediante la superposición de la obra de restauración sobre los restos de la obra original. De este modo, la acción de los agentes atmosféricos recaía directamente sobre la obra nueva y no sobre la histórica.

- Recuperar volúmenes perdidos, mediante la restitución de piezas desaparecidas y la recomposición de los paramentos incompletos y de las aristas que definían la geometría del conjunto. Se pretendía restablecer la continuidad formal de los cuerpos de fábrica para facilitar su lectura.

- Recuperar lecturas desaparecidas, mediante la preservación de las trazas de los sistemas de acabado, e incluso la reproducción parcial de los mismos sobre aquellos sectores de la fábrica restituidos por la restauración, de modo que se recuperasen las lecturas perdidas sin enmascarar la obra original.

Los criterios se fundamentaron en el más absoluto respeto hacia las estructuras a restaurar, tanto en sus características físicas (elementos, técnica constructiva, aparejo, material de trabazón...) como en su realidad estratigráfica. Fueron definidos a partir de la experimentación continua sobre obra real, y elaborados por un amplio equipo interdisciplinar formado por arqueólogos, arquitectos, historiadores del arte, restauradores, y muy en especial, por maestros artesanos de oficios, cuya aportación resultó esencial. Para todas las intervenciones que implicaron la incorporación de fábricas, se recurrió casi siempre al empleo de técnicas constructivas, materiales, elementos y aparejos iguales o similares a los originales, previa comprobación de su adecuado comportamiento, reversibilidad y compatibilidad con respecto a las fábricas históricas. También se reprodujeron el módulo de las piezas desaparecidas y el tratamiento de las juntas. Para ello se emplearon, siempre que fue posible, los materiales de construcción recuperados del subsuelo durante el proceso de excavación arqueológica manual, que eran separados por tipos y acopiados en puntos de vertido diferentes, dentro del yacimiento, de cara a su posterior reutilización en los trabajos de restauración. El objetivo era conseguir un alto grado de integración visual entre la obra de restauración y la original, y al mismo tiempo mantener a la vista la mayor cantidad de información posible acerca de la verdadera identidad constructiva de las fábricas históricas.

No obstante, este modo de proceder ponía en riesgo, a priori, el principio de autenticidad establecido por la legislación vigente y las cartas y convenciones internacionales. Para salvaguardarlo, se garantizó la diferenciación entre la obra de restauración y la original por diferentes medios, en función del tipo de obra de que se tratase. En las obras de mayor envergadura se utilizaron estratos de intervención interpuestos entre las fábricas históricas y las nuevas. Y la reposición se dejaba hueca al interior, también para no sobrecargar la estructura original. En las obras de sillería, las piezas de restitución fueron marcadas en sus caras ocultas con cortes de radial, como signo inequívoco de nuestro tiempo. En todos los casos se recurrió a la introducción de placas de cerámica industrial visibles desde el exterior, a modo de marcas de contorno. En la recomposición de obras de tapial la distinción se estableció a partir de la diferente coloración del material empleado en la restauración, o mediante la mezcla de este último con elementos de origen industrial ajenos a las estructuras históricas del yacimiento, como gravas basálticas de machaqueo. Por último, el exhaustivo proceso de documentación seguido antes, durante y después de cada intervención generó un completo corpus documental que sirve por sí mismo como instrumento de diferenciación entre fábricas originales y de restauración.

Se evitó recomponer las fábricas por encima de la cota máxima conservada para impedir que la restitución entrase en el terreno de la hipótesis. No obstante, para la protección de las coronaciones de los muros de mampostería o ladrillo se recurrió al añadido de algunas hiladas de sacrificio destinadas a absorber las agresiones de los agentes ambientales. En las estructuras de mayor envergadura, la coronación se protegió con capas de mortero hidrófugo dotadas de vertiente a ambos lados para evacuación de aguas pluviales. En la determinación de las cotas de coronación, se crearon líneas de remate escalonadas para evitar la formación de aristas de perfil visualmente agresivo, y para transmitir la idea de continuidad de la obra original en cotas superiores.

También se aplicó el criterio de mínima intervención, presente en las cartas y convenciones internacionales a partir de 1932. Las actuaciones se limitaron a los sectores de la fábrica histórica necesitados de consolidación, de modo que los que no presentaban problemas significativos permanecieron intactos. Así, se evitó la aplicación de rejuntados de 
restauración extensivos en cuerpos de fábrica completos, que hubiesen podido enmascarar las distintas unidades estratigráficas existentes, con la consiguiente pérdida de una parte de la carga documental del monumento.

Respecto a los procedimientos, cada intervención restauradora comenzaba con el replanteo inicial de la obra. La lectura de las marcas constructivas conservadas (líneas de fraguado diferencial, alveolos dejados por las piezas desparecidas, agujales, fronteras...) permitía conocer con precisión datos constructivos esenciales acerca de las fábricas a restituir, tales como la altura original de las hiladas de sillería o mampostería, o de los cajones de encofrado desaparecidos, y el módulo exacto o aproximado de las piezas a reponer. Estos detalles eran reproducidos a pie de obra, previamente al comienzo de la intervención propiamente dicha, mediante el empleo de reglas y cuerda siguiendo las directrices de la obra original, lo que permitía hacer una evaluación previa real del volumen de obra a ejecutar y facilitaba la selección de los elementos y la realización de ajustes.

Para recomponer fábricas de sillería o mampostería convencional, se elaboraba una propuesta de restitución concreta, sobre soporte gráfico, a partir de la cual se obtenían o seleccionaban las piezas necesarias, que después eran transportadas a pie de obra, presentadas en seco por hiladas en sus huecos para la realización de ajustes, y por último fijadas en su posición final con mortero de cal y arena. En cuanto a las juntas, siempre que fue posible se tendió a reproducir su tratamiento original. Cuando éste no se conservaba o no existía la suficiente certeza acerca de su configuración, se aplicaron rejuntados rehundidos que dejaban libres los contornos de cada pieza, lo que evitaba el enmascaramiento del aparejo y el empastado de la obra, y proporcionaba una textura y un acabado apropiados.

En las obras encofradas - tanto de mampostería como de tierra-, resultaba esencial la identificación de las marcas constructivas propias de esta técnica: juntas horizontales entre hileras sucesivas de tapias, juntas verticales o fronteras entre tapias consecutivas de la misma hilera, agujales, improntas de rejones... Su preservación tras la intervención restauradora era imprescindible para la adecuada percepción de la realidad constructiva original de este tipo de estructuras. Todas estas marcas fueron reproducidas en la cara vista de los muros en su posición exacta original.

Independientemente del tipo de material o técnica de que se tratase, se respetaron o reprodujeron todos aquellos detalles constructivos que transmitían información determinante acerca de la configuración de las partes desaparecidas de los edificios, o de los sistemas de refuerzo de la obra original, tales como mechinales para empotramiento de las vigas de forjados o cubiertas, almojayas para fijación de andamiajes, o negativos dejados por las armaduras de madera del interior de determinadas estructuras. Todos ellos fueron reproducidos o respetados en su posición original y con sus dimensiones exactas. En determinadas ocasiones, además, se dejaron a la vista testigos de madera insertos en dichos huecos, a modo de recurso didáctico.

Para la trabazón de las fábricas de restauración se empleó casi siempre mortero de cal y arena de composición y coloración similar al de la obra original. En aquellas intervenciones en que se precisaba de un fraguado más rápido que el propio de los morteros de cal, y con carácter excepcional, se admitió la adición de cemento blanco en proporciones muy bajas, para dar lugar a la formación del denominado mortero mixto o bastardo. Esta mezcla presenta una resistencia y velocidad de fraguado mayores que el mortero de cal, y un grado más alto de plasticidad y transpirabilidad que el mortero de cemento, pero menor contenido en sales que este último (Alejandre, 2002, p. 102).

\section{Conclusiones}

La comparativa entre las actuaciones previas y el plan de intervenciones sistemáticas en Calatrava la Vieja pone de manifiesto la necesidad de trabajar sobre la base de un conocimiento previo muy profundo del bien sobre el que se interviene. La intervención debe ser concebida a largo plazo, con vocación de continuidad, y estar sometida a una planificación general más allá de la mera solución de problemas concretos de conservación. Se requiere también la participación y la formación de profesionales altamente especializados y debidamente cualificados, y la continuidad en el tiempo de los equipos técnicos y científicos que encabezan los diferentes programas de actuación. 


\section{Referencias}

Alejandre Sánchez, F. J. (2002). Historia, caracterización y restauración de morteros. Sevilla: Secretariado de publicaciones de la Universidad de Sevilla.

Hervás Herrera, M. Á. (2016). Conservación y restauración en Calatrava la Vieja (1975-2010). Albacete: Universidad de Castilla-La Mancha, Repositorio Digital RUIDERA, URI: http://hdl.handle.net/10578/8711.

Hervás Herrera, M. Á., Juan García, A., y Retuerce Velasco, M. (2006). Alarcos y Calatrava: un territorio unido por el Guadiana. Investigación, restauración, difusión. En Al-Andalus, Espaço de Mundança. Balanço de 25 anos de História e Arqueologia Medievais (pp. 86-100). Mértola: Campo Arqueológico de Mértola.

Juan García, A. (2013). La patrimonialización de un yacimiento arqueológico: Alarcos (1984-2010). Tesis Doctoral. Ciudad Real: Universidad de Castilla-La Mancha.

Juan García, A., y Gómez Rodado, J. (2005). Parque Arqueológico de Alarcos-Calatrava. Escuela-Taller Alarcos. Un proyecto de empleo y formación para el patrimonio arqueológico. Boletín del Instituto Andaluz del Patrimonio Histórico, 54, 119-122.

Rascón, S., y Sánchez, A. L. (2000). Las Escuelas Taller y la formación profesional en torno a la arqueología. En Actas del III Seminari Arqueología i Ensenyament. Treballs d'Arqueología, 6 (pp. 91-115).

Sarthou Carreres, C. (1979). Castillos de España. Madrid: Espasa-Calpe. 